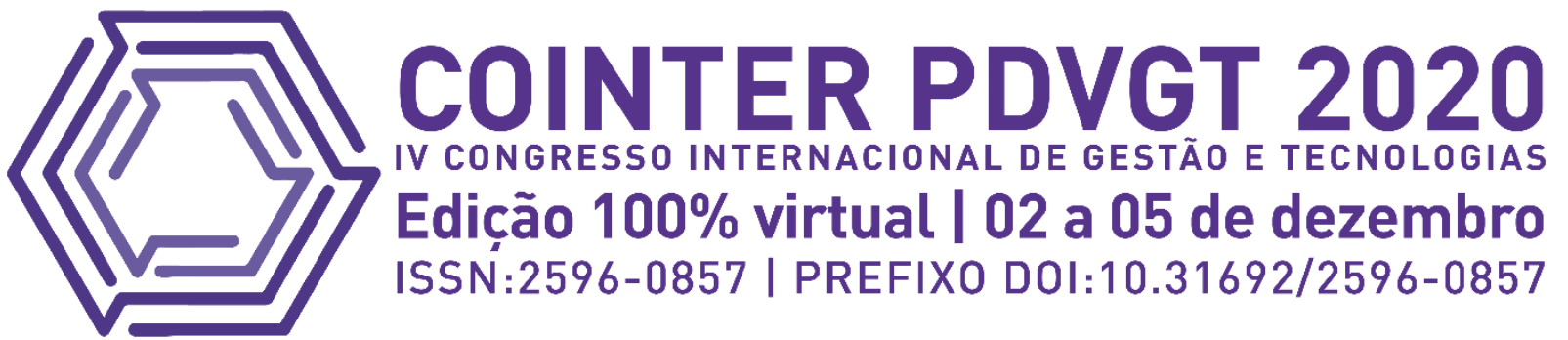

\title{
COMO JOGOS DIGITAIS AUXILIAM NO RACIOCÍNIO LÓGICO-MATEMÁTICO LOGICAL FALL
}

\section{CÓMO LOS JUEGOS DIGITALES AYUDAN AL RAZONAMIENTO LÓGICO- MATEMÁTICO \\ LOGICAL FALL}

\section{HOW DIGITAL GAMES ASSIST IN LOGICAL-MATHEMATICAL REASONING LOGICAL FALL}

\author{
Apresentação: Comunicação Oral
}

Enzzo Gabriel Marques Lopes ${ }^{1}$; Duana Camille da Rocha Fernandes de Queiroz ${ }^{2}$; Leidivânia Mendes de Araújo Melchuna ${ }^{3}$; Adriano Marques de Souza ${ }^{4}$;oel de Oliveira Santos ${ }^{5}$

DOI: https://doi.org/10.31692/2596-0857.IVCOINTERPDVGT.0082

\begin{abstract}
RESUMO
De acordo com os novos cenários de aprendizagem, torna-se necessário repensar o processo do ensinoaprendizagem e as práticas docentes, visto que algumas escolas ainda permanecem pautadas em um ensino tradicional, ou seja, existe a figura central do professor, o aluno que tem consigo o desinteresse no processo de aprendizagem e a escola por não conseguir atender as demandas do mundo contemporâneo. Sendo assim, os jogos digitais aparecem nesse contexto como um recurso didático que apresenta características que podem proporcionar uma série de benefícios para as práticas pedagógicas. Neste artigo, objetiva-se apresentar o jogo nomeado de "Logical Fall", criado por meio da engine Construct 3, o qual busca a melhoria acadêmica dos estudantes do ensino básico, nas áreas de Raciocínio Lógico e Matemática. Para tanto, foram utilizados recursos da lógica de programação com uso de poucos números, por meio de estratégias casuais, como, por exemplo, a criação de sistemas interativos entre o jogador e o ensino progressivo, isto é, o usuário busca melhorar o seu conhecimento ao jogar. $\mathrm{O}$ referencial teórico que norteia este trabalho encontra-se relacionado à ideia dos jogos e a sua lógica, introduzidos no contexto da educação, enfatizados em OLIVEIRA et al. (2019), RIBEIRO et al. (2015) e IVONE et al. (2008). Por fim, ao analisar alguns dados da plataforma em que o jogo "Logical Fall" foi hospedado, constatou-se a relevância da proposta e os benéficos para o público alvo, visto que, o jogo caracterizou-se como uma importante e viável alternativa para auxiliar em tais processos, por favorecer a construção do conhecimento do estudante.
\end{abstract}

\footnotetext{
${ }^{1}$ Técnico em Informática, Centro Estadual de Educação Profissional Professora Lourdinha Guerra/RN, enzzogabrielml@gmail.com

${ }^{2}$ Técnico em Informática, Centro Estadual de Educação Profissional Professora Lourdinha Guerra/RN, duana.vivian@gmail.com

${ }^{3}$ Mestra em Letras, Centro Estadual de Educação Profissional Professora Lourdinha Guerra/RN, leidivaniamel@gmail.com

${ }^{4}$ Especialista em Educação Matemática, Centro Estadual de Educação Profissional Professora Lourdinha Guerra/RN, marquesmat50@gmail.com

${ }^{5}$ Pós-graduando em Tecnologias Aplicadas à Educação, Centro Estadual de Educação Profissional Professora Lourdinha Guerra/RN, joeloliveira56@gmail.com
} 
Palavras-Chave: Educação, Jogos, Lógica.

\section{RESUMEN}

De acuerdo con los nuevos escenarios de aprendizaje, se hace necesario repensar el proceso de enseñanza-aprendizaje y las prácticas de enseñanza, ya que algunas escuelas siguen basándose en la enseñanza tradicional, es decir, existe la figura central del maestro, el estudiante que tiene el desinterés por el proceso de aprendizaje y la escuela por no poder satisfacer las exigencias del mundo contemporáneo. Así, los juegos digitales aparecen en este contexto como un recurso didáctico que presenta características que pueden aportar una serie de beneficios para las prácticas pedagógicas. En este artículo, el objetivo es presentar el juego denominado "Logical Fall", creado a través del motor de la Construct 3, que busca el perfeccionamiento académico de los estudiantes de educación básica, en las áreas de Razonamiento Lógico y Matemáticas. Para ello, se utilizaron recursos lógicos de programación, utilizando pocos números, a través de estrategias casuales, como por ejemplo, la creación de sistemas interactivos entre el jugador y la enseñanza progresiva, es decir, el usuario busca mejorar sus conocimientos al jugar. La referencia teórica que guía este trabajo está relacionada con la idea de los juegos y su lógica, introducida en el contexto de la educación, enfatizada en OLIVEIRA et al. (2019), RIBEIRO et al. (2015) e IVONE et al. (2008). Finalmente, al analizar algunos datos de la plataforma donde se alojó el juego "Logical Fall", se verificó la relevancia de la propuesta y los beneficios para el público objetivo, ya que el juego se caracterizó como una alternativa importante y viable para ayudar en dichos procesos, al favorecer la construcción del conocimiento de los estudiantes.

Palabras Clave: Educación, Juegos, Lógica.

\section{ABSTRACT}

According to the new learning scenarios, it becomes necessary to rethink the teaching-learning process and teaching practices, since some schools still remain based on traditional teaching, that is, there is the central figure of the teacher, the student who has the disinterest in the learning process and the school for not being able to meet the demands of the contemporary world. Thus, digital games appear in this context as a didactic resource that presents characteristics that can provide a series of benefits for pedagogical practices. In this article, the objective is to present the game named "Logical Fall", created through the Construct 3 engine, which seeks the academic improvement of basic education students, in the areas of Logical Reasoning and Mathematics. To this end, programming logic resources were used, using few numbers, through casual strategies, such as, for example, the creation of interactive systems between the player and progressive teaching, that is, the user seeks to improve his knowledge when playing. The theoretical reference that guides this work is related to the idea of games and their logic, introduced in the context of education, emphasized in OLIVEIRA et al. (2019), RIBEIRO et al. (2015) and IVONE et al. (2008). Finally, when analyzing some data from the platform where the game "Logical Fall" was hosted, it was verified the relevance of the proposal and the benefits for the target audience, since the game was characterized as an important and viable alternative to assist in such processes, by favoring the construction of student knowledge.

Keywords: Education, Games, Logic

\section{INTRODUÇÃO}

As Tecnologias da informação e comunicação (TICs) estão ampliando cada vez mais a interação entre pessoas, por exemplo, no mundo acadêmico, exercem funções que propiciam a comunicação entre professor e estudante, além disso, também propomove a interação do ser humano com a Inteligência Artificial (IA), seja no Smartphone, Personal Computer (PC), ou 
em outro meio que faça uso de uma tecnologia avançada.

Outro meio, em que as TICs podem ser utilizadas é na melhoria do entendimento dos alunos, e na compreensão dos assuntos dentro ou fora da sala de aula. Esses podem ser realizados por métodos convencionais da informação, quais sejam: vídeos, áudios, artigos científicos, e-book, ou por outros métodos que são considerados inovadores. Nesse caso, um modelo que está ganhando bastante espaço nessa área são os jogos digitais.

No campo matemático, a maioria dos estudantes apresenta dificuldades imensas em relação a vários assuntos, mas há também conteúdos nesse ramo que se tornam fáceis, por serem ensinados de forma lúdica. Nesse caso, o processo de aprendizagem é mais dinâmico e traz consigo novas possibilidades de interação entre os estudantes e o professor, tornando o conteúdo mais atrativo. Isso é comprovado por $\operatorname{BESSA}(2007$, p. 4) quando relaciona alguns fatores que comprometem o aprendizado.

"[...] ao professor (metodologias e práticas pedagógicas), ao aluno (desinteresse pela disciplina), à escola (por não apresentar projetos que estimulem o aprendizado do aluno ou porque as condições físicas são insuficientes) ou à família (por não dar suporte e/ou não ter condições de ajudar o aluno).”.

Diante do exposto, percebe-se a importância da atividade lúdica no processo de ensinoaprendizagem, visto que, de acordo com a Assessora Especial de Tecnologias da Secretaria Estadual de Educação de São Paulo (SEE SP, 2017), o jogo em si, incentiva os alunos em torno de um objetivo, respeitando e direcionando diferentes papéis aos envolvidos que, no final, unem-se em um todo para aprimorar o conhecimento individual de cada um.

Desse modo, o conceito geral de um jogo constitui-se em, ter um objetivo principal, seguir regras e adquirir mecanismos que auxiliem em cada etapa, por exemplo, em jogos de aventura, como: “Tetris”, para avançar de um determinado local ao outro, é preciso ter um nível de conhecimento, concluindo os "Puzzles" e também os desafios propostos no cenário atual em que a personagem/jogador encontra-se.

Seguindo a linha de raciocínio de Benjamin (2002. p. 33), "é equivocado desenvolver exigências isoladamente, enquanto o espírito de sua totalidade se mantiver vedado a cada uma dessas exigências em sua realização". Nesse sentido, deve haver um foco ao realizar alguma ação e, caso não haja o aprendizado daquela ferramenta, será colocado no vazio cerebral.

Segundo Garofalo (2017), “os games trabalham o raciocínio lógico, ao desenvolver pensamentos estratégicos e dedutivos.". Nesse aspecto, compreende-se que existem situações em que os jogos são mais um auxílio do que um problema na vida de crianças e adolescentes, principalmente na resolução de problemas. Sendo assim, com base no exposto, objetiva-se a criação de um jogo digital para dispositivos mobiles com o intuito de auxiliar o raciocínio lógico 
matemático do público-alvo (crianças e adolescentes), visto que há certa dificuldade na área de ensino, principalmente nos ramos da matemática, lógica e raciocínio humano.

\section{FUNDAMENTAÇÃO TEÓRICA}

\section{Educação e relações sociais}

A Educação destina-se a ser a própria criação do homem para fundamentar a socialização entre pessoas. Desde pequenos, o indivíduo é inserido nesse contexto social e um dos lugares primordiais para obter-se educação é na escola, nela o ser humano inicia os primeiros passos para o aprendizado. Não obstante, a compreensão da importância dessa temática ainda é desconsiderada por muitos. É verdade que a reivindicação pelo acesso a uma educação de qualidade para todas as crianças e adolescentes existe, porém ainda há problemas para concretizar essa ideia. Isso é comprovado quando se observa os índices do IDEB (2019), principalmente no ensino médio, visto que as metas para o desenvolvimento da educação básica não foram atingidas, pois não atingiu a média esperada em 2019 foi alcançada, estimada de 5.0 . 112):

Contudo, ainda se observa uma realidade preocupante, segundo Benjamin (2002, p.

$$
\begin{aligned}
& \text { "a educação burguesa das crianças menores é, em consonância com a situação da } \\
& \text { classe da burguesia assimétrica. Evidentemente a burguesia possui o seu sistema } \\
& \text { educacional. A desumanidade de seus conteúdos trai-se, contudo exatamente pelo fato } \\
& \text { de que estes fracassam em relação à infância mais nova". }
\end{aligned}
$$

Analisando a data do documento, percebe-se que exite uma diferença de 20 anos de em relação ao ano de 2020. Contudo, esse tema ainda causa um grande efeito sobre a sociedade que, por sua vez, desconhece mudanças significativas. Sendo assim, todas as crianças e os jovens, que não tem acesso à educação de qualidade, recebem práticas educativas de formas diferentes, focados em sua maioria, apenas no material essencial que em muitos casos é escasso. Essa infomação é justificada ao compararmos as notas obtidas nas escolas particulares em relação às públicas IDEB (2019).

Desse modo, pode-se concluir que os fatores sócio-econômicos influenciam no processo de ensino e aprendizagem, visto que nem sempre os estudantes menos favorecidos tem acesso a uma educação publica e de qualidade, o processo de melhoria do ensino público é continuo, porém ainda existem lacunas no processo de ensino e aprendizagem.

\section{Jogos e a relação com a aprendizagem}

Os jogos estão cada vez mais se popularizando, principalmente com o avanço das TICs, 
no Brasil, segundo dados da PGB (2020), 73,4\% dos brasileiros afirmam ser jogadores de diversos jogos, o que representa um aumento de 7,1\% em relação ao ano anterior.

Dentre as diversas áreas dos jogos, verifica-se a junção do lazer com o aprender, e por isso, os jogos também são almejados na educação. Essa ideia é reforçada por CALISTO et al. (2010. p.1):

"Jogos educativos fornecem uma importante contribuição na aprendizagem, pois são
ambientes capazes de manipular grandes informações, representadas de maneiras
diversas, através de imagens, textos, sons, filmes etc."

Diante do exposto, existem alguns trabalhos publicados na literatura que demostram as perspectivas da utilização de jogos no processo de ensino e aprendizagem conforme a Tabela 01.

Tabela 01: Trabalhos Relacionados

\section{AUTOR RESUMO}

A meta desta pesquisa foi definir prováveis relações entre questões que OLIVEIRA et rodeiam raciocínios lógico e matemático na performance de 26 crianças, al. (2019) distribuídas em dois grupos (fortes e fracos, marcados, primeiramente, pelo seu desempenho em matemática - aritmética).

Este estudo tem por objetivo identificar as teorias de aprendizagem aplicadas

RIBEIRO et em jogos digitais educacionais desenvolvidos no Brasil no período de 2004 al. (2015) a 2014. Foram analisados 27 artigos, selecionados com o auxílio da base de dados do Google Acadêmico, para isso, foram utilizados dois grupos de descritores.

IVONE et al. (2008)

Neste trabalho, efetuou-se uma pesquisa de campo através de análises e aulas de educadores de matemática dos primeiros anos de Ensino Fundamental e consultas bibliográficas.

Fonte: própria (2020)

A concentração imposta em jogos é algo muito relevante para o "aprender", como por exemplo, no jogo "The Legend of Zelda: Ocarina of Time", onde se é colocado à prova de enigmas relativamente complexo e, para passá-los, é necessário usar certos conhecimentos, que são adquiridos com o tempo. Desse modo, mesmo que o jogador não perceba, está construindo um auto-guia, um caminho fixo no qual segue trilhando uma linha de raciocínio, algo que é padronizado, por conseguinte, a maioria das vezes é apresentada uma dinâmica em uma fase, nas fases seguintes é testada a mesma, até o jogador conseguir compreender a complexidade da dinâmica.

Essa linha de pensamento é algo que acontece no "Rift Racoon", um jogo em que o protagonista é um guaxinim que tem de passar por várias fases. O jogo em si, tem uma mecânica 
simples, em certos momentos do jogo pode-se usar um teletransporte para passar de fases, esta mecânica torna-se crucial e indispensável para avançar no jogo, logo, as primeiras fases do jogo servem para exercitar e conhecer mais sobre a mesmo, visto que, como afirma La Taille (1992, p.17):

"[..] a capacidade de pensar simultaneamente o estado inicial e o estado final de alguma transformação efetuada sobre os objetos (por exemplo, a ausência de conservação da quantidade quando se transvaza o conteúdo de um copo A para outro $\mathrm{B}$, de diâmetro menor) evidência este estágio e lhe garante base para o estágio seguinte".

Considerando que os diversos gêneros de jogos estimulam o usuário a alcançar objetivos simples ou complexos, verifica-se que as suas mecânicas podem estimular de forma positiva o processo de ensino-aprendizagem.

\section{A lógica e o processo de agir}

A lógica é um processo corriqueiro na vida das pessoas, sem ela, algumas ações não podem ser realizadas, ou talvez fiquem sem sentido. Nesse aspecto, segundo La Taille; Oliveira e Dantas (1992, p.17), "lógica representa para Piaget a forma final do equilíbrio das ações. Ela é um sistema de operações, isto é, de ações que se tornaram reversíveis e passíveis de serem compostas entre si”.

Os processos lógicos são fortemente atrelados a Matemática, a relação que existe entre os números e as operações básicas de adição, subtração, multiplicação e divisão, são exemplos básicos desse processo. Nesse sentido, como diz Dante (2010, p.22):

"Para resolver problemas, precisamos desenvolver determinadas estratégias que, em geral, se aplicam a grande número de situações. Esse mecanismo auxilia a análise e a solução de situações em que um ou mais elementos desconhecidos são procurados."

Os problemas descritos na citação anteiror, se fazem presentes na lógica matemática que é representada no jogo "TuxMath" (Figura 01), um jogo antigo que pode ser encontrado facilmente no sistema operacional Linux Educacional que muitas escolas públicas utilizam, o jogo abrangia uma gama de conhecimento, uma vez que para proteger os habitantes de cometas que caiam vagarosamente, o jogador tinha que acertar as contas matemáticas que apareciam, assim ele poderia acumular pontos e passar das fases. 
Figura 01: Print do jogo "TuxMath"

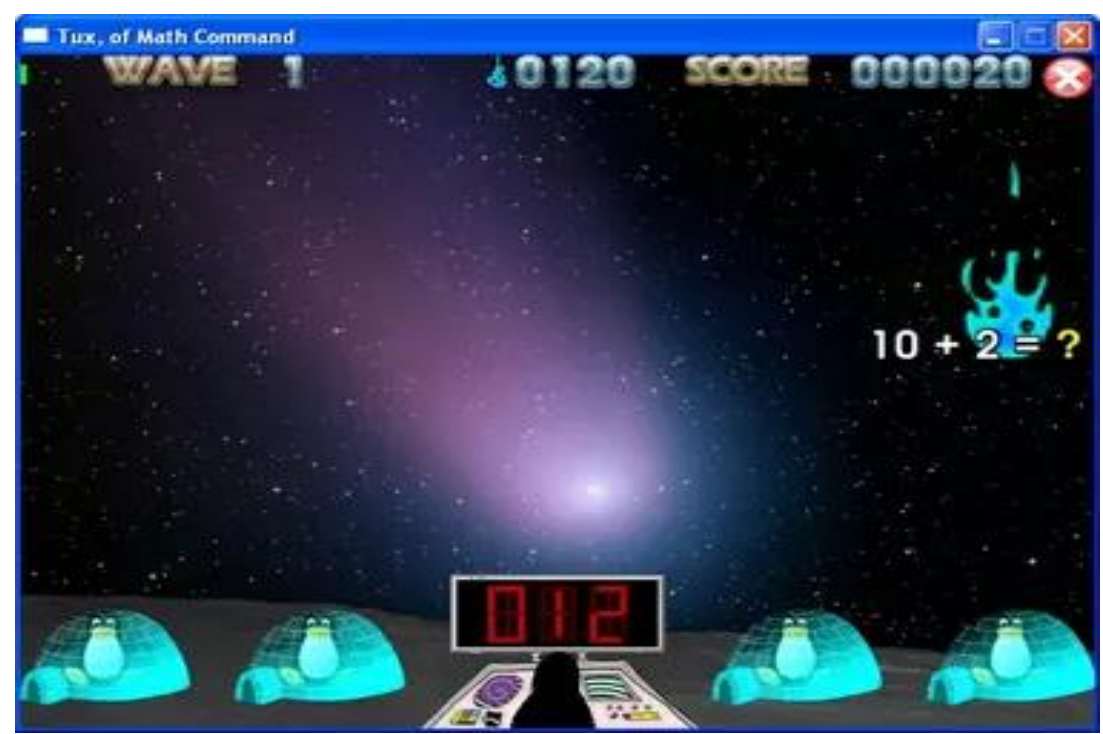

Fonte: tuxmath.br.uptodown.com (2008)

Neste sentido, a lógica e o conhecimento básico das quatro operações, conectado com o raciocínio exigido para calcular e acompanhar a velocidade do jogo, possibilita melhorias no processo de racicionio lógico e por conseguinte ajuda em diversas áreas de conhecimento.

\section{METODOLOGIA}

A metodologia é dividida em duas partes, a primeira trata sobre os materiais usados para a construção do jogo, e a segunda os métodos na qual dialoga sobre como funcionam os sistemas lógicos do jogo.

\section{MATERIAIS}

Os materiais utilizados para construção do jogo foram o Construct $3^{6}$ que é a engine selecionada e o Piskel que é o programa usado para a construção dos elementos gráficos.

O Construct 3 foi utilizado para a construção do jogo, pois já tinhamos um conhecimento prévio da ferramenta. O programa é dividido em duas partes, (1) o layout onde se pode visualizar o projeto e a inserir elementos para compor o cenário, e a (2) folha de eventos, onde se encaixa a programação, podendo ser, por exemplo, em javascript, porém feita em blocos de eventos com situações diferentes para cada um.

Os elementos gráficos do jogo são constituidos de pixel art, esse estilo gráfico é a criação de arte com Pixel (pixels no plural), definida segundo Fleming (2018) como: "aglutinação de picture e element, ou seja, elemento de imagem, sendo pix a abreviatura em 
inglês para pictures.". Para isso, foi utilizada a ferramenta Piskel 0.14.0, pois mostrou-se bastante eficaz na construção de sprites em pixel art.

\section{MÉTODOS}

Os métodos consistem em detalhar a parte lógica por trás da construção do jogo, na qual é subdivida em quatro partes principais: Classe principal, Spawn, Captura de ORB's, sistemas universais/salvamento de jogo e ranqueamento.

\section{Classe Principal}

A lógica principal do jogo são os $\mathrm{Orbs}^{7}$, eles caem com um determindado tempo e possuem cores e pontuações distintas. Dada essas informações, o objetivo principal do jogo é capturar essas Orbs e conseguir chegar a um limite de pontos solicitado.

Há uma pontuação limite inserida no jogo, ao iniciar cada rodada é definida uma pontuação entre 50 e 200, essa pontuação precisa ser atingida para passar de nivel. Nesse processo ocorre a captura de Orbs e deve-se atingir exatamente o valor solicitado no decorrer de 60 segundos.

Ao coletar cada Orb, uma pontuação diferente é adicionada:

- ORB BLUE (Azul): +01 pontos;

- ORB PURPLE (Roxa): +05 pontos;

- ORB YELLOW (Dourada): +10 pontos;

- ORB RED (Vermelha): -Número aleatório $(1,10)$.

Desse modo, o ritmo do jogo é construído. Ao coletar as orbs e atingir o valor socicitado dentro de 60 segundos, passa-se de fase, caso o tempo seja expirado, volta para o "HUB".

\section{Spawn}

Neste tópico, é conceituado como ocorre a criação dos objetos principais do jogo, as Orb's. Para isso, é necessário compreender o conceito de spawn que é basicamente o processo de nascimento de algo, nesse caso, as Orb's do jogo.

O sistema de aleatoriedade vem a acontecer por meio de um processo pré-definido, a cada $X$ segundos nascerá, de uma posição distinta no jogo, uma Orb, na qual contém o comportamento da gravidade, definida em "100”, conforme Figura 02. 
Figura 02: Fluxograma parte 01, criação das orbs

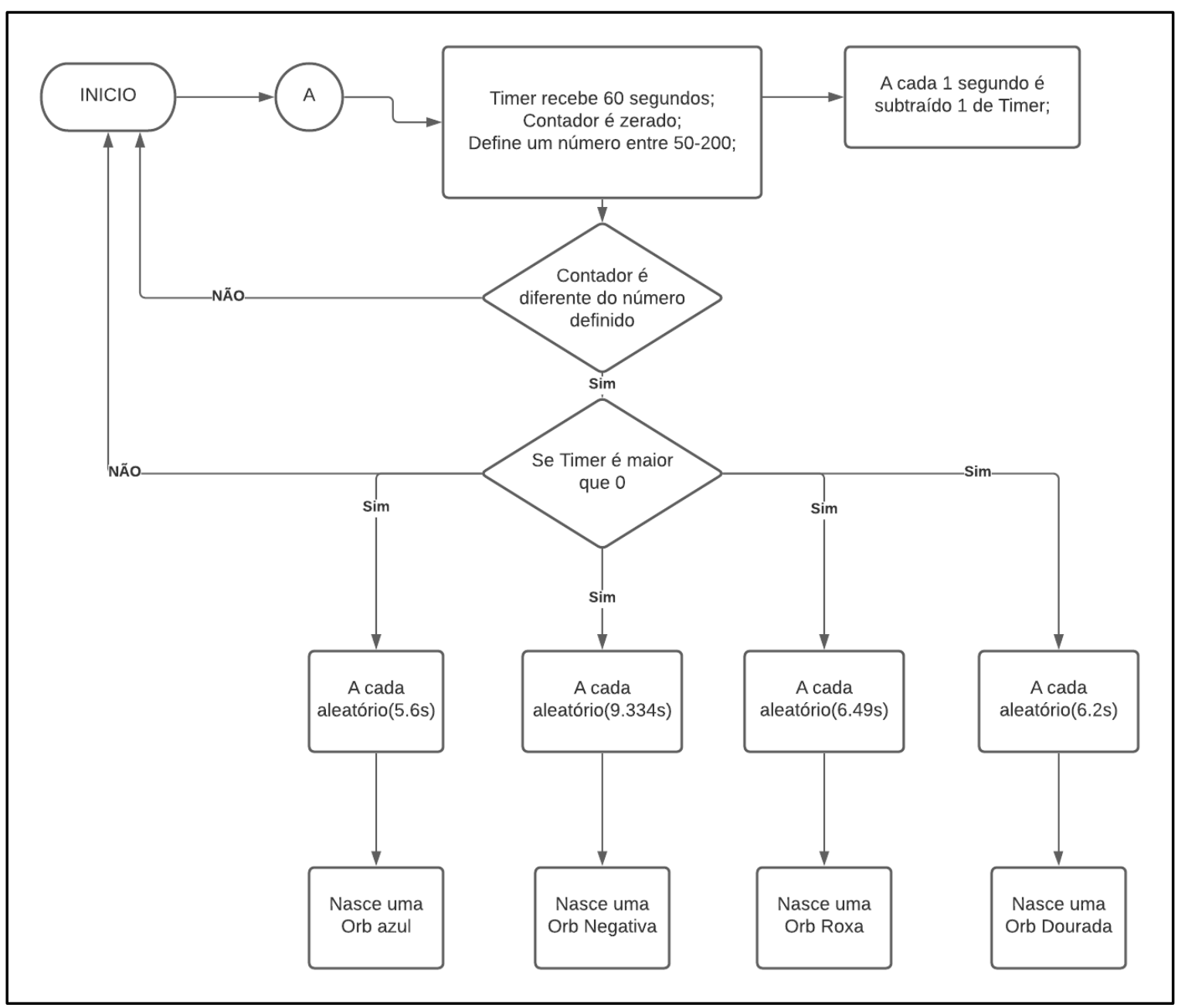

Fonte: própria (2020)

Observa-se que na figura 02 é especificado o conceito de retorno, caso a pontuação seja igual ao número definido, a IA interpreta que o sistema deve retornar para o "HUB" do jogo, o mesmo processo acontece quando o tempo do jogo que, inicialmente foi definido em 60 segundos, decai até chegar a zero, atingindo essa marca, o jogo é imediatamente redirecionado para o $H U B$.

\section{Captura de ORBs}

É possível realizar a captura de quatro ORBs distintas sendo três delas: azul, amarelo e roxo para adição de pontução e a vermelha ou negativa para a subtração de potuação. Existe uma restrição no sistema, na qual as ORB's devem ser capturas até o limite de tempo.

Em um exemplo comum, faltando 10 segundos para a rodada acabar, o jogador tem que coletar 100 pontos, ele já está com 98, em seguida, aparece uma Orb Vermelha e uma Amarela, a primeira citada irar retirar um número aleatório e esse número pode ser 8 , o que seria suficiente 
para ele pegar a amarela e, consequentemente, adquirir 10 pontos para chegar aos exatos 100 , pontos suficientes para passar da fase. Conforme Figura 03.

Figura 03: Fluxograma parte 02, coleta de ORBs

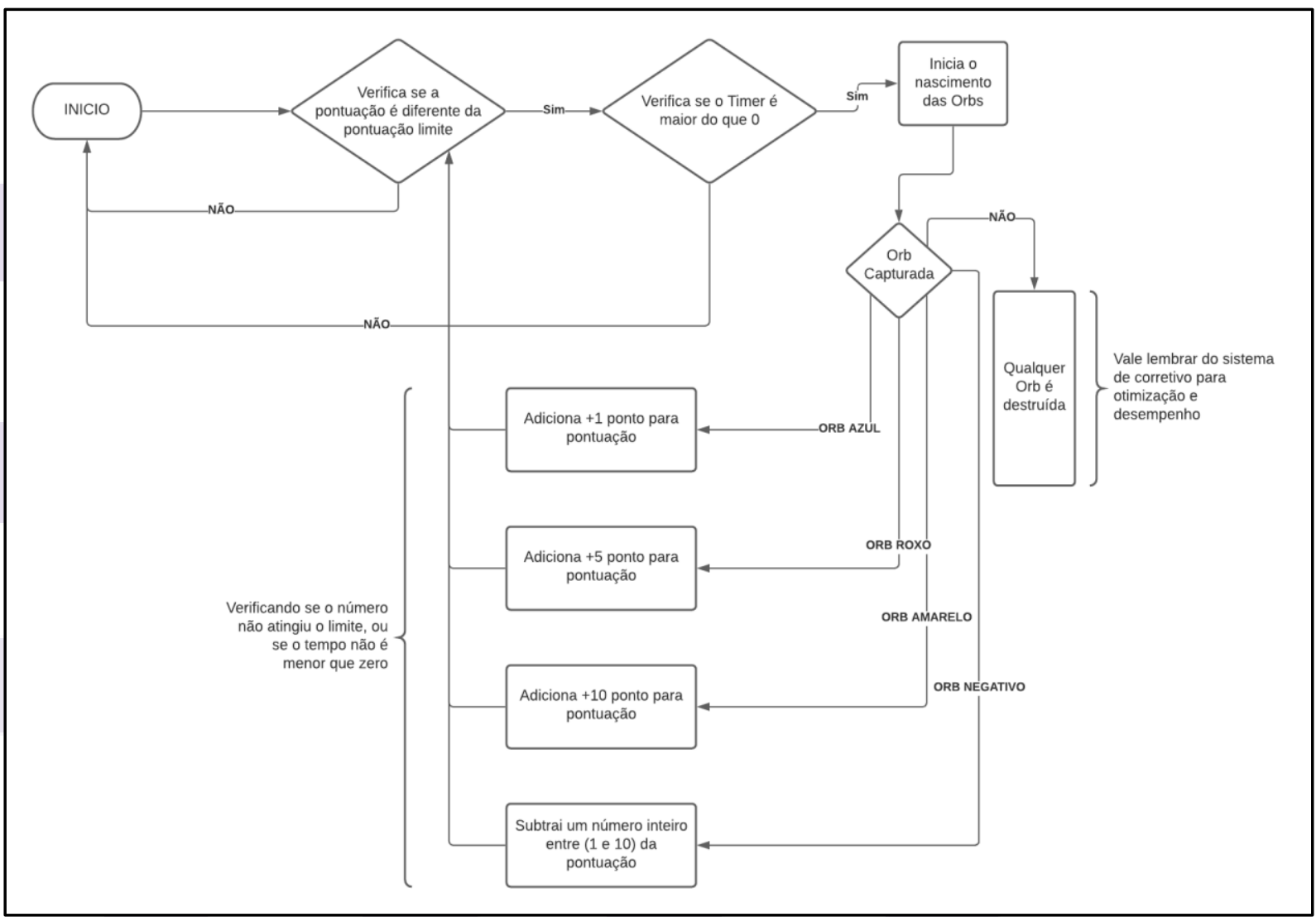

Fonte: própria (2020)

Para não haver problemas em desempenho gráfico e no motor do jogo, há um componente de programação, feito exclusivamente para quando as ORBs que não forem capturas sejam automaticamente destruídas.

\section{Sistemas universais e salvamento de jogo}

Os sitemas universais foram desenvolvidos para obter uma melhora visual nas telas do jogo para isso, foi utilizado o sistema "HSL color" que consiste em: Hue (Matiz), Saturation (Saturação) e Lightness (Iluminação). No projeto funciona da seguinte forma, a variável de controle definida acrescenta número de 0 até 100 em milésimos de segundos, e após ultrapassar 100, ela retorna para 0 , assim criando um loop infinito. A programação do sistema entende que esse loop é encaixado no HSL da imagem, onde a saturação e a iluminação não é interferida, apenas a Matiz da imagem, mudando de vermelho para amarelo e assim em diante até completar o ciclo, e que foi determinado que ele se repetisse infinitas vezes. Conforme Figura 04. 
Figura 04: Fluxograma parte 03, salvamento do jogo, sistema de cores

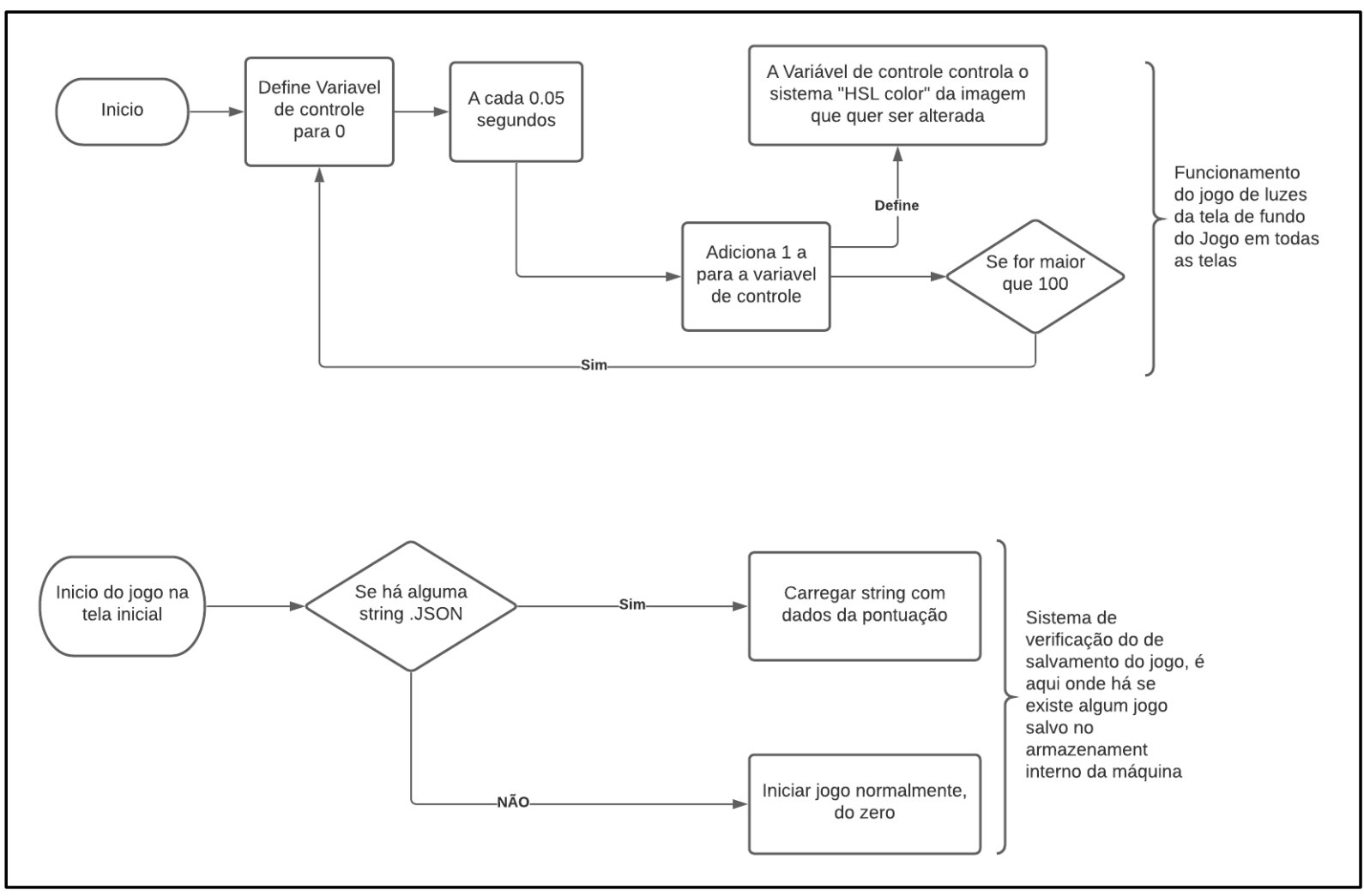

Fonte: própria (2020)

A área de salvamento do jogo consiste em dois processos, o primeiro é o processo de leitura, ao salvar o jogo, é criada uma string JSON no armazenamento local do jogo, na qual todas as informações são guardadas, em seguida é criado um compartimento na máquina onde o jogo está instalado.

A string por sua vez tem a função de conter dados importantes, e como o jogo trabalha apenas uma informação essencial, ela se define apenas como a variável global da pontuação "Recorde". O fluxo de salvar pontos inicia-se a partir do momento que o jogador perde, ou sai da tela de jogo e volta para o menu, assim que inicia o menu, automaticamente a variável é salva como uma string JSON e é armazenado na pasta que o sistema definir como banco de dados do jogo. No Sistema Operacional Android", ele fica armazenado na pasta "obb"10 dependendo do arquivo. Conforme Figura 05. 
Figura 05: Fluxograma parte 04, ativação do sistema salvo.

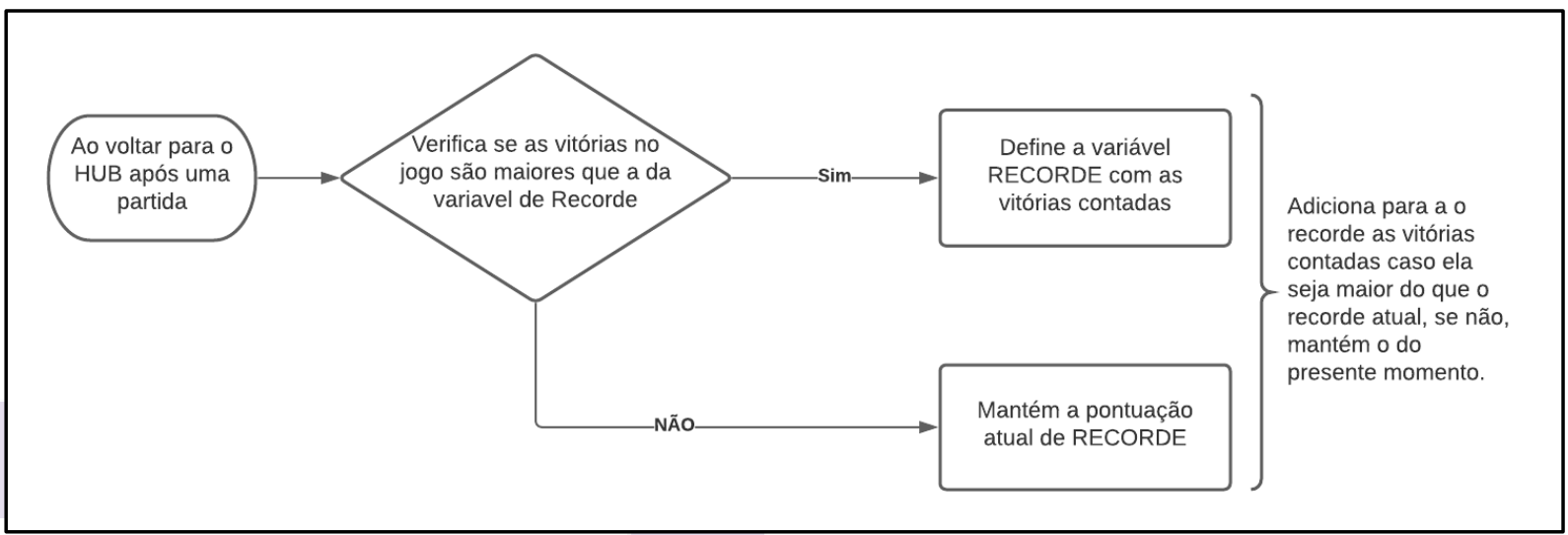

Fonte: própria (2020)

\section{Ranqueamento}

O sistema de raquemaneto é divido entre seis categorias, baseadas no nível de experiência durante o jogo, apresenta-se em formas de troféus. Sendo o Diamante, o nível acima de 200 pontos de recorde acumulado, e o "Sem Rank” quando a pontuação é abaixo de 10.

- Sem classificação (Sem Rank);

- Cobre;

- Prata;

- Ametista;

- Ouro;

- Rubi;

- Diamante;

O sistema de ranqueamento foi criado para despertar o instinto competitivo. É uma característica comum do ser humano, o querer ser ambicioso, mas não confunda a ambição com a ganância nesse caso, porque, conforme Cortella (2020), "uma pessoa ambiciosa é aquela que 'quer mais'; uma pessoa gananciosa é aquela que 'quer só para si, a qualquer custo".

As próximas seções tratarão sobre a avaliação do jogo.

\section{RESULTADOS E DISCUSSÃO}


Após o detalhamento de todo o processo de construção do jogo, é possivel ter uma noção dos aspectos do LOGICAL FALL nas imagens explicitadas nessa seção. Em geral, o projeto foi estruturado de uma forma que pudesse chamar a atenção e que também fosse de fácil manueseio, na Figura 06 é possível observar a interface do jogo.

Figura 06: Print da tela inicial do LOGICAL FALL.

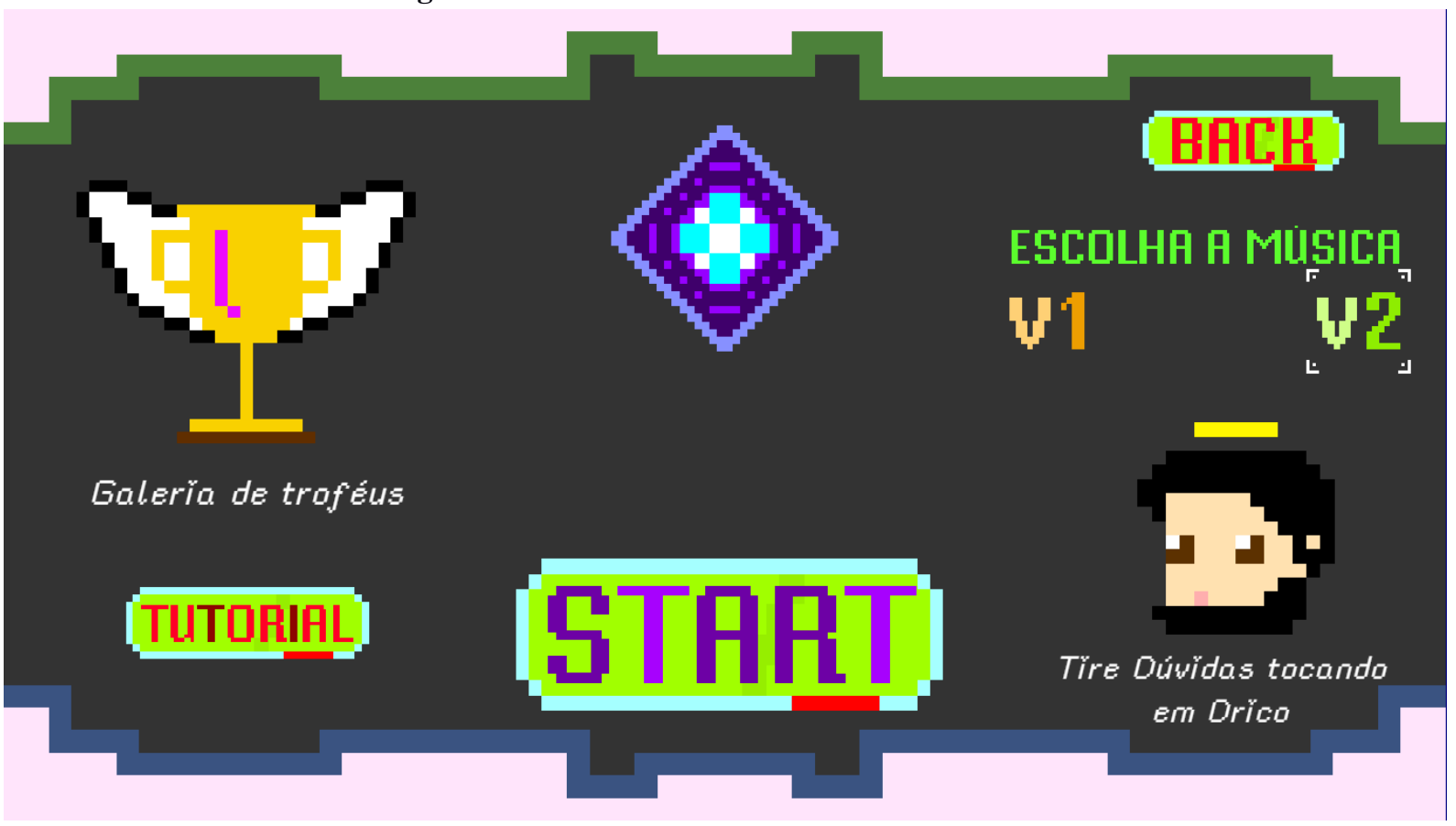

Fonte: própria (2020)

O cenário emite um sistema de iluminação conforme apresentado na metodologia (Métodos - Sistemas unviersais e salvamento de jogo) e as letras também seguem o mesmo padrão, possui uma tela interativa com um personagem único no jogo e a presença de um seletor musical, caso deseje optar por duas músicas, estas que foram compostas por Mari Sampaio. A ferramenta para iniciar o jogo é bem nítida, o Start deixa evidente que basta clicar nele e o participante é direcionado para a Zona (Figura 07) onde o jogo começa.

A Zona do jogo está exemplificada abaixo na Figura 07, nela podemos observar como ocorre a dinamica da captura de Orbs, também é detalhado na Tabela 01 os componentes presentes na Zona. 


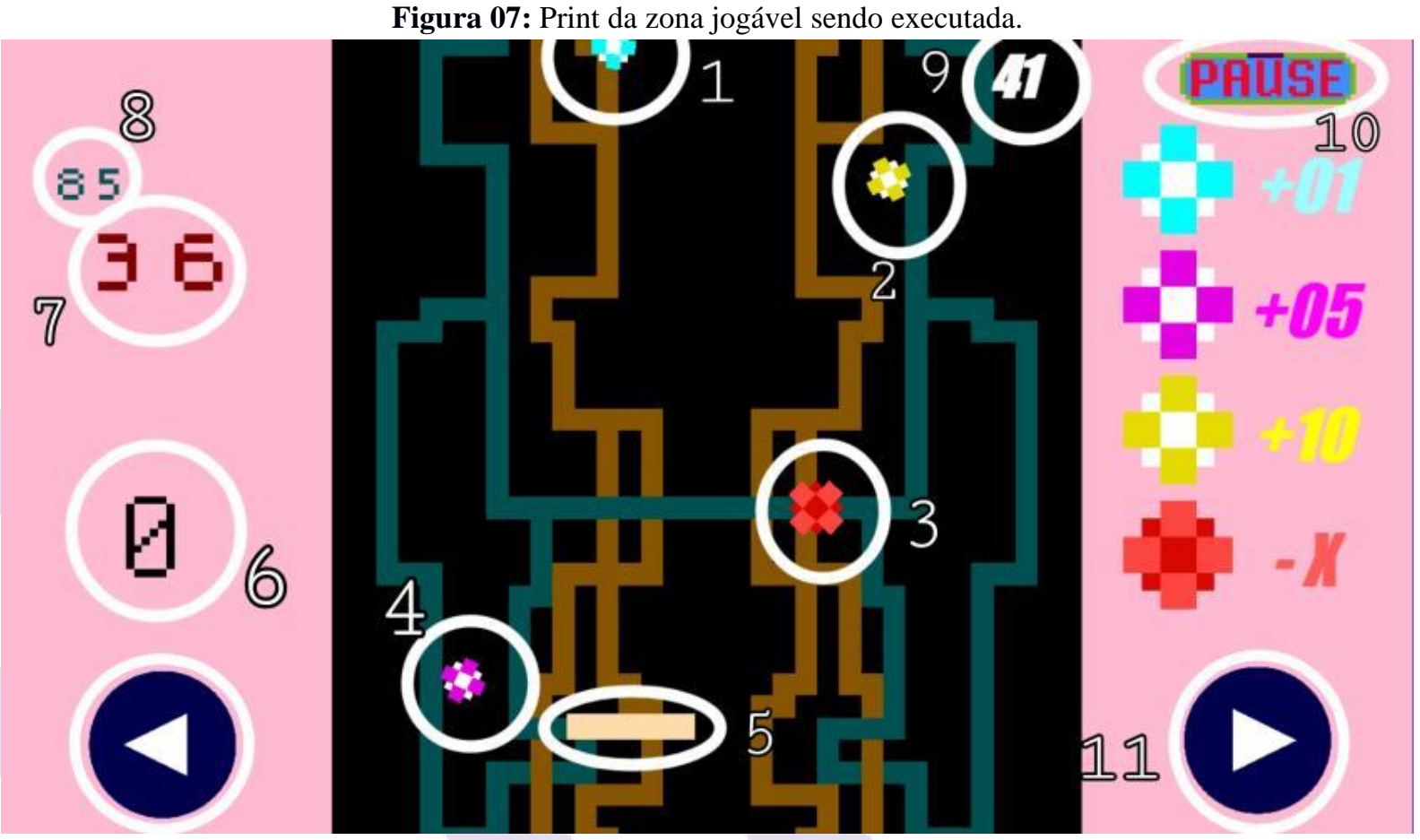

Fonte: própria (2020)

Tabela 02: Legenda da figura 10.

\begin{tabular}{cc}
\hline Número & Significado \\
1 & Orb Azul, acrescenta pontuação \\
2 & Orb Amarela, acrescenta pontuação \\
3 & Orb Vermelha ou negativa, retira pontuação \\
4 & Orb Roxa, acrescenta pontuação \\
5 & Capturador, quem pega as Orbs na partida \\
6 & Pontuação Acumulada de Vitórias nas rodadas \\
7 & Pontuação da rodada atual \\
8 & Pontuação a qual o jogador tem que chegar na medida exata \\
9 & Tempo cronometrado de 60 segundos até 0 segundos \\
10 & Botões sincronizados com o Touch Screen da máquina \\
11 & Fausa \\
\hline
\end{tabular}

Fonte: própria (2020) 


\section{Avaliação do jogo}

O jogo já foi publicado na Google Play e para tentar validadar a contribuição do jogo, foram extráidas informções sobre a avaliação dos usuários, essas informações são disponibilizadas pelo próprio sistema da Google, algumas estatistiscas podem ser observadas nas próximas imagens (Figura 08 e Figura 09).

Figura 08: Print da visão geral das notas do jogo.

\begin{tabular}{|c|c|c|}
\hline Q Pesquisar Play Console & & (D) \\
\hline Classificações & & Acessar "Fazer o download de relatórios" \\
\hline \multicolumn{3}{|l|}{ Visão geral } \\
\hline- & $4.973 \star$ & 37 \\
\hline Nota do Google Play (2) & Nota média do ciclo de vida: (2) & Usuários (2) \\
\hline
\end{tabular}

Fonte: Google Play Console do jogo (2020)

Com o jogo publicado na plataforma, extraiu-se algumas estatísticas sendo uma delas a de avaliação de usuários, que varia de 0 a 5 estrelas e nesse ponto, 37 usuários avaliaram o jogo e a média foi de 4.9, sendo assim, considerado um jogo excelente dentre os usuários avaliadores.

No dia do lançamento (10 de out de 2020), houve um grande número de instalações do jogo, e pode-se observar que existe uma grande relação se for analisado a avaliação e o volume de instalações do jogo que é bem recente. Conforme o gráfico da Figura 09.

Figura 09: Print da visão geral das notas do jogo.

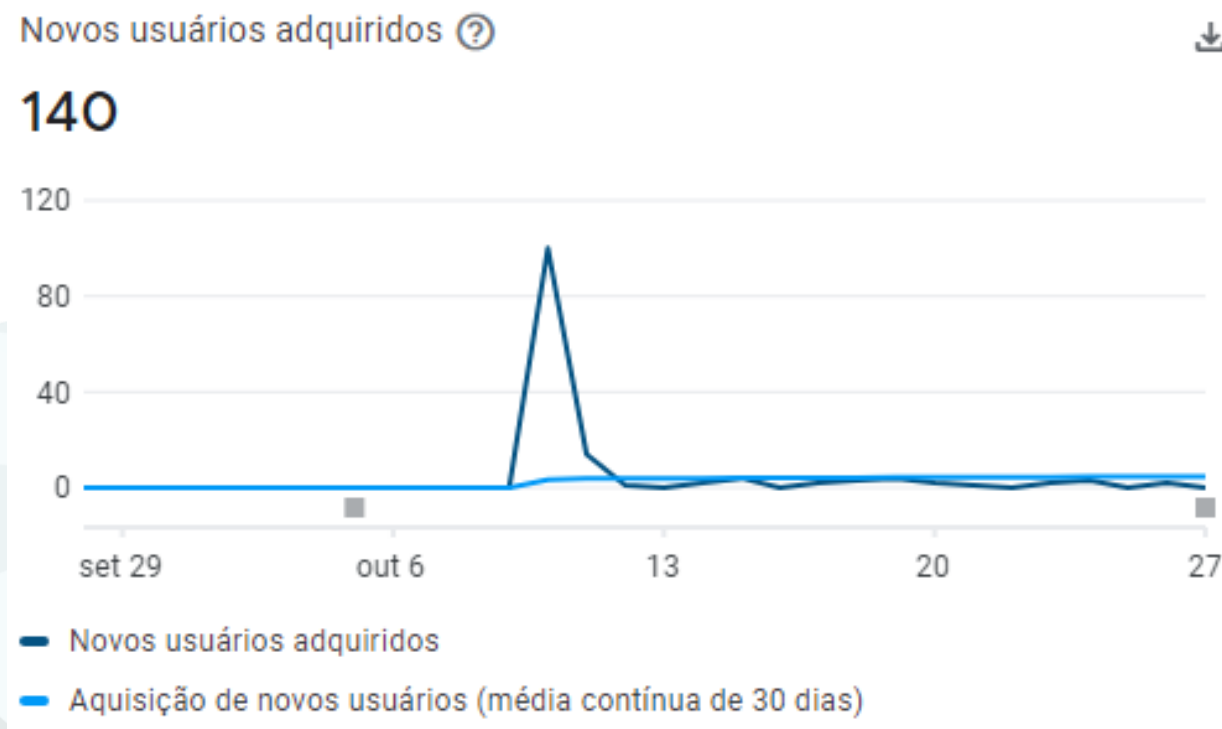

Fonte: 'Google Play Console’ do jogo "Logical Fall” (2020)

Sendo assim, pode-se observar nas avaliações que o Logical Fall possui relevância para 
com o processo de ensino-aprendizagem na área de matemática.

\section{CONCLUSÕES}

Foi possível observar durante o processo de desenvolvimento do projeto que o estudo dos beneficios dos jogos para educação é algo bastante significativo, uma vez que proporciona uma aprendizagem lúdica, por meio de mecanismos que auxiliam nos pensamentos e na construção do conhecimento, desenvolvendo competências e habilidades nas crianças e adolescentes, portanto, descontruindo ideias errôneas sobre o uso dessa ferramenta lúdica na sociedade.

Nesse sentido, o jogo "Logical Fall” promoveu uma melhoria no ensino de matemática, a partir de interações lúdicas com os jogadores, estimulando o raciocínio lógico, concentração e, principalmente, uma aprendizagem engajada com as expectativas dos estudantes.

Por fim, considerando os resultados obtidos na avaliação do jogo "Logical Fall”, é possível determinar que os objetivos foram atendidos de modo positivo, visto que, após as avaliações dos usuários, constatou-se a relevância de sua aplicação para a melhoria dos processos pedagógicos no ensino básico.

\section{REFERÊNCIAS}


BENJAMIN, Walter. Reflexões sobre a criança, o brinquedo e a educação. São Paulo: Livraria Duas Cidades, 2002.

BESSA, Karina Petri. Dificuldades de aprendizagem em matemática na percepção de professores e alunos do ensino fundamental. Universidade Católica de Brasília, 2007.

CALISTO, André; BARBOSA, David; SILVA, Carla. Uma análise comparativa entre jogos educativos visando à criação de um jogo para educação ambiental. In: Brazilian Symposium on Computers in Education (Simpósio Brasileiro de Informática na Educação-SBIE). 2010.

CORTELLA, M. S., Cooperar para não exaurir. Disponível em <https://pt.linkedin.com/pulse/cooperar-para-n\%C3\%A3o-exaurir-mario-sergio-cortella $>$ Acessado em 16 de set de 2020.

FLEMING, A.., O que é Pixel Art?. Disponível em $<$ http://www.pixstudios.com.br/blog/novidades-de-computacao-grafica-e-games/o-que\%C3\%A9-pixel-art> Acessado em 20 de set de 2020.

GAROFALO, Débora, 5 motivos para usar games da aula de matemática, 2017. Disponível em: $<$ https://novaescola.org.br/conteudo/6776/5-motivos-para-usar-games-na-aula-dematematica>. Acesso em 27 de julho de 2020.

IVONE et al. A aprendizagem da matemática através de jogos e brincadeiras Disponível em: $<$ https://semanaacademica.org.br/system/files/artigos/artigo_cientifico_semana_academica_re vista_cient.pdf $>$ Acesso em 14 de nov de 2020.

IDEB, Índice de Desenvolvimento da Educação Básica, Resultados e metas, 2019.

Disponível em: $\langle$ http://ideb.inep.gov.br/resultado/resultado/resultadoBrasil.seam?cid=88227 $>$ Acesso em 11 de nov de 2020.

OLIVEIRA, et al. Correlação entre o Raciocínio Lógico e o Raciocínio Matemático em Crianças Escolarizadas, 2019. Disponível em:https://www.scielo.br/pdf/bolema/v33n65/19804415-bolema-33-65-1047.pdf $>$ Acesso em 13 de nov de 2020.

PGB, Pesquisa Game Brasil, Perfil demográfico e comportamental dos Gamers, 2020. Disponível em:< https://www.pesquisagamebrasil.com.br/pt/> Acesso: 11 de nov de 2020.

RIBEIRO et al. Teorias de aprendizagem em jogos digitaise educacionais: um panorama brasileiro, 2015. Disponível em: < https://www.seer.ufrgs.br/renote/article/view/57589 > Acesso em 14 de nov de 2020. 